\title{
Psycho-educational Intervention for Caregivers of Head and Neck Cancer Patients; An experimental initiative from India
}

\author{
Marie M Nympha ${ }^{1}$, Dr Mary Venus Joseph ${ }^{2}$, Dr Bino Thomas ${ }^{3}$ \\ ${ }^{I}$ PhD Research Scholar, Department of Social Work, Christ University, Karnataka, India \\ ${ }^{2}$ Dean and Administrator, Rajagiri College of Social Sciences, M.G. University, Kerala, India \\ ${ }^{3}$ Asst. Prof and Head, Department of Social Work, Christ University, Karnataka, India
}

\begin{abstract}
Head and neck cancer patients experience greater psychosocial problems and functional disabilities than other cancer patients because of the location of the disease and treatment. Consequently, it hampers their activities of daily living, making them dependent on the care giver. Eventually, caregivers have several needs, especially during the initial phase of hospitalization as they are unprepared for the task, lack the required knowledge and skills in care giving. Thus they face a number of problems in all the spheres of their life. Hence, this study is aimed to understand their needs, develop a psycho educational intervention program based on it and assess its feasibility. It was taken up because of limited number of Indian studies and increase in the number of incidences owing to the changing life style. Exploratory research design was used to assess the feasibility of the program. 30 family caregivers of head and neck hospitalized cancer patients undergoing curative treatment were selected using survey method. Needs were assessed using standardized tool. Intervention program was developed and implemented, after which, qualitative and quantitative data was collected to assess its feasibility. Findings indicated that the intervention program was feasible and beneficial to the care givers and the patients.

Keywords: Care Givers, Cancer, Interventions, Oncology, Psycho education.
\end{abstract}

\section{Introduction}

Head and neck cancer is a broad term that includes carcinomas (95\% fall under squamous cell) of the head and neck region [1]. It constitutes around one third of the whole cancer incidents in India, with nearly 2 lakh new cases reported every year [2].

\subsection{Problems encountered by people with head and neck cancers}

People with head and neck cancer experience psychiatric symptoms and disorders at greater rates than in other cancer patients [3].They have to put up with several kinds of problems like discoloration of the skin, mucositis, disfigurement, dysphagia, drooling, dryness of the mouth, trismus, speech impairment, tube feeds etc that leads to social withdrawal, isolation and sexual problems[4]. They experience functional impairment, decreased quality of life, psychosocial changes and decreased social interactions because of the centrality of the diseased area [5-7]. Such deficits may exist for years regardless of treatment success $[8,9,4]$. As a result the patients are dependent on their family caregiver [10].

\subsection{Impact of Care Giving on Care givers}

Care givers are the core part of long term health care [25]. They impart 55\% of active care to the patient at home and during hospitalization [37, 38]. Studies have discovered that cancer affects all their domains such as their physical, psychological, social, financial and spiritual well being [11-14], thereby making them secondary patients [15]. It is more profound for caregivers of head and neck cancer patients because of the prominent location of the disease affecting the prime organs necessary for daily living (food consumption, breathing and communication). Therefore these patients would be more dependent on their care givers because of which they would need help from health care providers to sustain their role [16]. Research has established that cancer patients and their care givers have an interdependent relationship [17]. Therefore, the more the health care professional help caregivers, the more the patients would be benefited [18].

Research has also indicated that caregivers experience high level of burden, strain and distress while caring for an ill family member [19-21] and alleviating it has important social and economic benefits [22]. It can be achieved through interventions.

\subsection{Interventions for care givers}

Interventions are the helpful change strategies that are recommended and imparted by health care clinicians to alleviate the burden of care giving [23]. They are designed to enable the caregivers to become more 
competent, confident and skilled and in turn enhance patient care [15]. Literature has shown that family caregivers have participated in intervention programs which have focused exclusively on improving patient outcomes like symptom management with less attention towards their needs [24]. Therefore interventions must be based on caregiver assessment which identifies their problems, needs, resources and strengths [25]. Studies have revealed that caregivers have psychosocial needs which must be addressed in order to maintain their health and provide the best possible care to the patient [26].

A qualitative study on twenty-five caregivers of brain tumor patients had found that caregivers provided extraordinary uncompensated care involving significant amount of time and energy for months or years, performing tasks that often hindered all the spheres of their life. They had to constantly solve problems and make decisions as the care needs changed. But, however they felt untrained and unprepared as they struggled to adjust to the new roles and responsibilities. In addition as their focus was on the patients, their needs were neglected [27].Therefore studies have proved the need to develop effective interventions to meet their needs from the diagnosis to end of life so that they can maintain their own health and impart best possible care to the patient [26-30]. Thus this study is aimed to develop psycho educational intervention program for caregivers of head and neck cancer patients based on their needs.

\subsection{Scope of this paper}

This paper is relevant in the present scenario because head and neck cancer is on the rise owing to the changing life style [31], increased use of tobacco, alcohol and oral sex [32, 33]. Secondly it takes a toll on the caregivers of head and neck cancer patients because of the location of the disease, side effects of the treatment and enhanced five year survival rate of the patients (50\% and above) [3]. Therefore health care professionals have attempted to understand the concept and impact of care giving and have designed interventions to ameliorate their negative impact. But most of the intervention studies were from the west with caregivers of people in the palliative stage of the illness and with caregivers caring for patients at home. It has also proven that Indian intervention studies on caregivers of head and neck cancer patients are relatively limited. They experience high level of stress and burden during the initial phase of the treatment and thus there was the need to develop appropriate interventions [7, 34]. Hence this paper is an attempt to develop Psycho educational program for the family care givers of people with head and neck cancer, during the initial phase of hospitalization and undergoing curative treatment.

\subsection{Research Design}

\section{Methodology}

An exploratory research design was used to assess the feasibility of the psycho educational intervention program. In the same study both qualitative and quantitative methods was used. This is called as mixed methods research [35]. Qualitative and quantitative data was collected after delivering the intervention modules.

\subsection{Operational definition of Care Giver}

In this study caregiver is defined as any family member (male or female), above 18 years and below 70 years, related through marriage or blood (Spouse, Parents, Siblings, Children or in-laws) and who imparts unpaid care (physical, psychosocial support) to people with head and neck cancer during the hospitalization.

\subsection{Sampling and Sample Size}

The universe of the study was 40 caregivers of head and neck cancer patients admitted in Vydehi Institute of Medical Sciences and Research Center. It was a small number and therefore, all of them who met the inclusion criteria were included. Using survey method 30 caregivers of head and neck cancer patients were selected. One patient did not have a caregiver, one caregiver was not willing to participate owing to personal problems, 5 were illiterate, one caregiver was reluctant to leave the patient and come for the intervention program and 2 were old patients.

\subsection{Tool for data collection}

\subsubsection{Cancer Care Givers Needs Assessment Interview Schedule}

It was a self developed, standardized, semi structured interview schedule. The first part of the tool was used to elicit the socio demographic profile of the caregiver and clinical details of the patient. It consisted of 108 items. The dimensions were Informational Needs (27 items), Psychological Needs (28 items), Family Needs (12 items), Social Needs (8 items), Financial Needs (13 items), Personal Needs (10 items) and Spiritual Needs (10 items). Each item was scored on a three -point Likert scale. The scoring assigned was as follows: never -0 , sometimes -1 and always -2 points. The internal consistency of the tool was established using Cronbach's Alpha. The alpha value was 0.899 . 


\subsubsection{Interview Schedule to test the Feasibility of the intervention program}

It was a simple, non standardized, self developed tool, used to assess the feasibility of the intervention program. It consisted of 10 items with yes/no answers. The items were as follows:

1. All the sessions of the Intervention program was useful. Yes/No

If no, which of the sessions were not useful, specify

2. We were able to understand the sessions. Yes/No

If no, which of the sessions were difficult to comprehend, specify

3. Time allotted for each session was adequate. Yes/No

If no, specify which session was too lengthy /elaborate

4. All the sessions were interesting. Yes/No

If no, specify which session was of disinterest to you

5. Do you think that such intervention programs must be implemented in hospitals? Yes/No

If no, specify why?

6. Do you feel the need for more number of sessions? Yes/No

If no, specify why?

7. Were the sessions delivered to your expectation? Yes/No

If no, specify what was lacking in the sessions

8. Was the content of the sessions relevant to meet your needs? Yes/No

If no, specify why?

9. Did the sessions disrupt your schedules? Yes/No

If yes, specify the ideal time for such programs

10. Do you think it is possible for you to practically implement what you have learnt? Yes/No.

\subsection{Data Collection}

The purpose and process of the research was explained to the care givers who met the inclusion criteria and signature was taken on the consent forms. Data was collected from 30 caregivers of people with head and neck cancer using interview schedules and in depth interviews.

\subsection{Statistical analysis}

Percentage and mean scores of total needs was calculated to analyze different requirements. Higher the total score, greater was the need. Percentage was used to assess the Psycho educational intervention program. Analysis was done using SPSS soft ware. Content Analysis was used to analyze Qualitative data.

\section{Phases of Intervention}

\subsection{Phases in the development of the psycho educational intervention program}

\subsubsection{Phase- I: Assessment of Psychosocial Needs}

The needs of Caregivers of head and neck cancer were assessed by using the Cancer Caregivers Needs Assessment Interview Schedule. It was constructed using in-depth interviews and focused group discussion with the care givers, extensive literature review, discussion with experts and experience of working with them. It was a standard tool. Data was collected from 30 care givers of patients with head and neck cancer. The data was coded, entered in SPSS and analyzed. The Needs of the Caregivers of People with Head and Neck Cancer based on the Total Scores were as follows:

Total Needs: Social needs were the highest $(81 \%)$ followed by financial need $(65 \%)$, psychological Needs $(63 \%)$, informational needs $(56 \%)$, personal needs $(55 \%)$ family needs $(50 \%)$ and spiritual need $(50 \%)$.

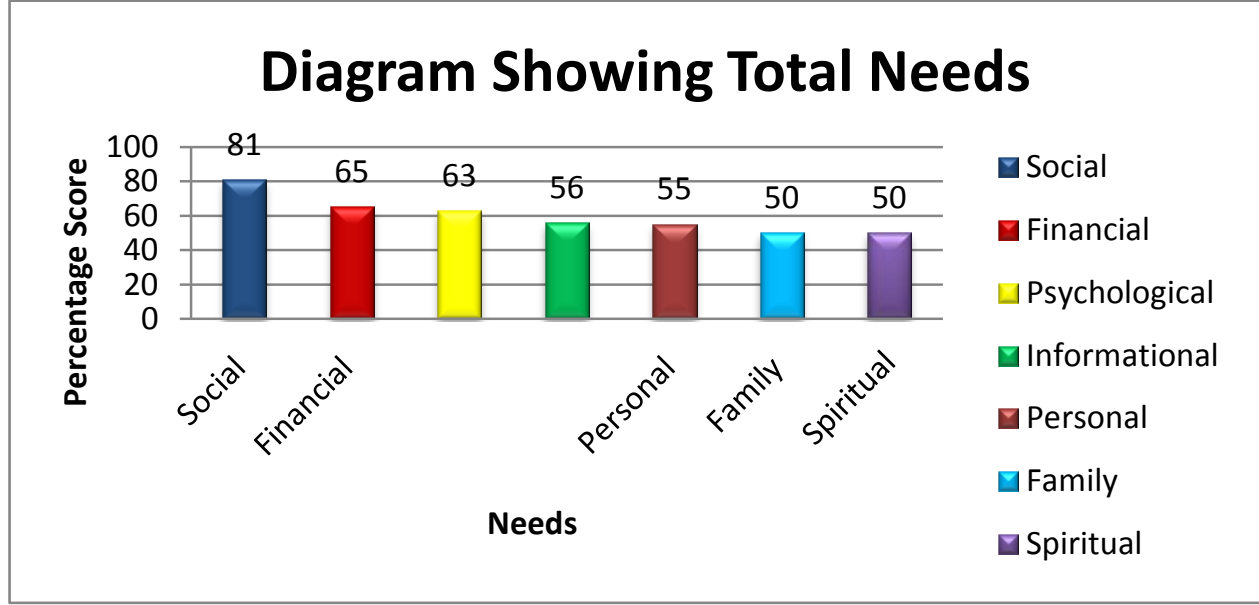

*Higher the score, higher the need. 
The main aim was to understand their needs and develop a psycho educational intervention program for care givers of people with head and neck cancer based on it.

\subsubsection{Phase-II: Developing the intervention Program}

The intervention program was developed based on the needs of the caregivers using literature review, discussing with the experts, experience gained from clinical practice and discussing with the caregivers. Expert guidance was sought before and after developing the intervention program with prior appointments. A street play was developed in the local language "Kari Neralu Karagidhaga" for the rural caregivers and recorded. It was used to clarify myths like cancer is a non communicable disease, questions pertaining to causes, disseminate information on the signs and symptoms, stages of the disease, modalities of treatment, Do's and Don'ts and the importance of being compliant to the treatment and facilities imparted by the government.

\subsubsection{Phase - III: Validating the intervention program}

The intervention program was framed and given to 10 experts in the field. Based on their feedback the changes were incorporated and two modules were added one on Spirituality and the other on Medical Management of the Illness, after which ethical clearance was obtained.

\subsubsection{Phase -IV: Data Collection for the main study}

In this stage, caregivers who satisfied the inclusion criteria were selected as the sample group using survey method. The purpose of the research and the intervention program was explained to them and consent forms were signed. Depression, Anxiety and Stress Scale (DASS-21) [36] was administered to rule out cases of depression. It was followed by 6 sessions of intervention program. Post test was done to assess the feasibility of the intervention program using self constructed interview schedule and in depth interviews.

\section{Psycho-educational intervention program}

It consisted of 6 modules. The duration of each module was 1- 2 hours.

Module -1: The goal of this module was to enable the care givers to acknowledge their self worth, recognize their needs and develop a care giver plan to meet them.

Module -2: The goal was to enable the care givers of head and neck cancer patients to identify the stressors and learn strategies to cope with it.

Module -3: It aimed at enabling the care givers to understand the disease, stages, treatment modalities, side effects and the precautions to be taken.

Module - 4: This module was an extension of the previous module which aimed at enhancing the knowledge of the care givers on the medical management of the illness like handling tube feeds, type of nutrition, techniques in managing tracheotomy tube, maintaining hygiene, managing side effects of the treatment, Do's and Don'ts, what to expect and when.

Module -5: It enabled the caregivers to explore their meaning in suffering, their meaning of life and address their spiritual distress.

Module -6: The aim of this module was to facilitate the care givers to identify their daily problems and equip themselves with Problem Solving Skills (Pearlman) that could be used.

\subsection{Clinical Details of the Patients}

V. Findings

The Mean age of the patient was 51 years, $77 \%$ of the patients were female and $23 \%$ were male. All of them suffered from Head and Neck Cancers and were hospitalized. They were in the initial phase of curative treatment.

\subsection{Description of the Caregivers based on their socio demographic profile}

The Mean age of the caregiver was 34 years. $60 \%$ of the caregivers were male and $40 \%$ were female. $70 \%$ of the caregivers were the children of the patients, $27 \%$ were their spouses and $3 \%$ were parents. Most of the caregivers were school dropouts (40\%), 30\% completed SSLC, $20 \%$ were educated up to PUC and $10 \%$ were graduates. Most of the caregivers were employed (63\%). The percentage of unemployed caregivers were $30 \%$ and $7 \%$ were students. Majority of the caregivers were farmers (58\%), the percentage of skilled laborers were $32 \%$ and $10 \%$ were businessmen.57\% of the caregivers were married and $43 \%$ were unmarried. $12 \%$ had no children, $18 \%$ had one child, $29 \%$ had 2 children, $29 \%$ had 3 children and $12 \%$ had more than 3 children. All the caregivers and patients were from the rural regions of Karnataka and they were below poverty line. They had a Below Poverty Line card and therefore the treatment cost of the patients was covered under Arogya Vajpayee Scheme. 
Table No 1 Showing Distribution of Caregivers based on the Socio-demographic details

\begin{tabular}{|l|l|l|}
\hline Sl. No & Socio-demographic details & Mean \\
\hline 1. & Caregiver's age & 34 \\
\hline
\end{tabular}

\begin{tabular}{|c|c|c|c|}
\hline $\begin{array}{l}\text { Sl. } \\
\text { No }\end{array}$ & Socio-demographic details & Categories & Percentage \\
\hline \multirow[t]{2}{*}{2.} & \multirow{2}{*}{ Gender of care giver } & Male & 60 \\
\hline & & Female & 40 \\
\hline \multirow[t]{3}{*}{3.} & \multirow{3}{*}{ Relationship with patient } & Parents & 03 \\
\hline & & Spouse & 27 \\
\hline & & Children & 70 \\
\hline \multirow[t]{4}{*}{4.} & \multirow{4}{*}{ Qualification of care giver } & School Dropout & 40 \\
\hline & & SSLC & 30 \\
\hline & & PUC & 20 \\
\hline & & Graduate \& above & 10 \\
\hline \multirow[t]{2}{*}{5.} & \multirow{2}{*}{ Work } & Employed & 63 \\
\hline & & Unemployed & 30 \\
\hline & & Students & 07 \\
\hline \multirow[t]{3}{*}{6.} & \multirow{3}{*}{ Nature of employment } & Farmers & 58 \\
\hline & & Skilled Laborers & 32 \\
\hline & & Businessmen & 10 \\
\hline \multirow[t]{2}{*}{7.} & \multirow{2}{*}{ Marital Status } & Married & 57 \\
\hline & & Unmarried & 43 \\
\hline \multirow[t]{4}{*}{8.} & \multirow{4}{*}{ Number of children } & No Children & 12 \\
\hline & & 1 Child & 18 \\
\hline & & 2 Children & 29 \\
\hline & & 3 Children \& above & 41 \\
\hline
\end{tabular}

\subsection{Quantitative assessment of the psycho educational intervention program}

All the care givers of people with head and neck cancer said that the intervention program was useful, easy to understand, interesting and it must be implemented in all the hospitals. $87 \%$ of the care givers said that the content was adequate while $13 \%$ said that they needed more information. $97 \%$ of the caregivers wanted more number of sessions and the remaining $3 \%$ said that the number of sessions was adequate. All the caregivers said that their needs were met. When asked whether the program disrupted care giving, $57 \%$ said no and the remaining $43 \%$ said yes but yet they said the program was beneficial and so it must continue. All the care givers said that they were able to practically implement the program in their daily tussle with care giving.

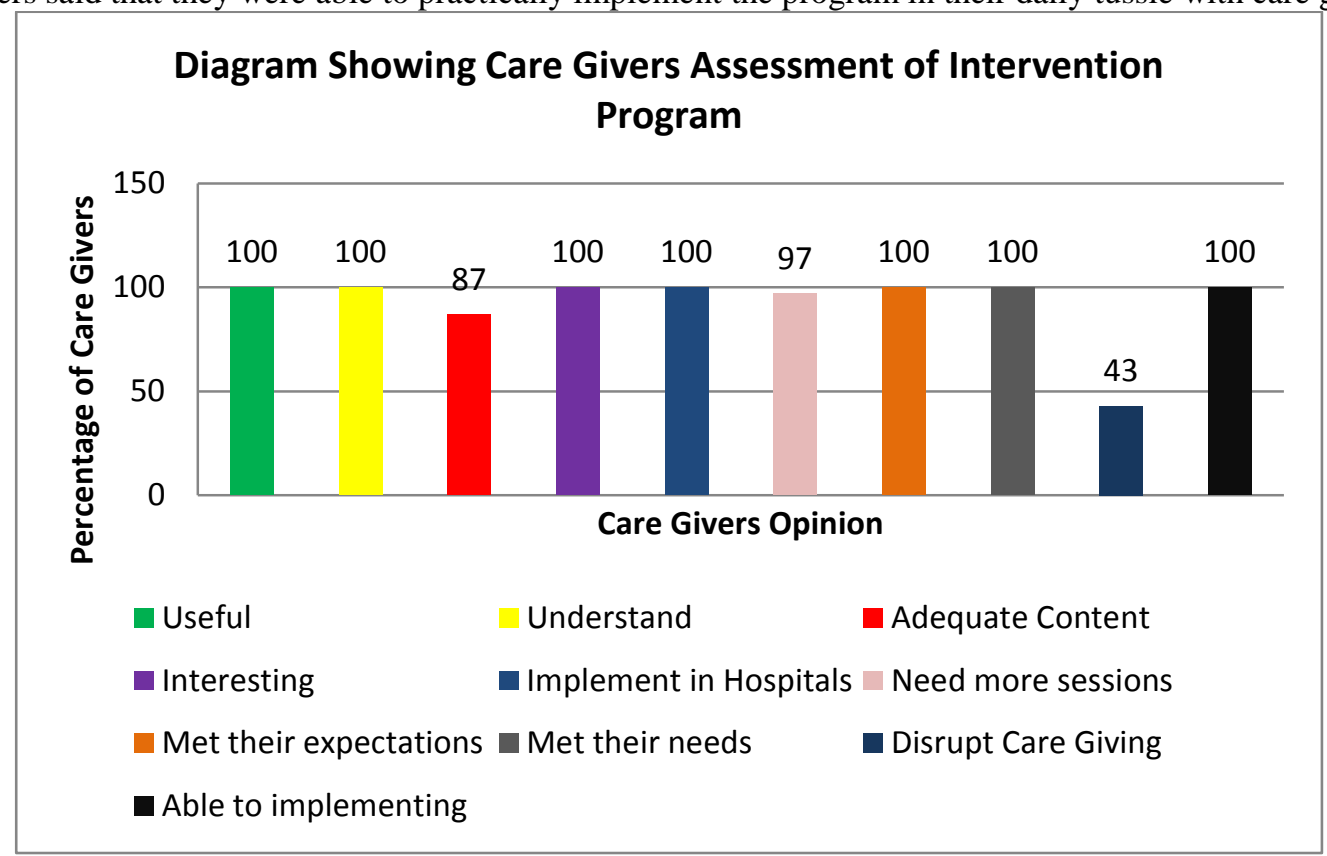




\subsection{Qualitative assessment of Psycho educational intervention program}

Majority of the care givers said that after the intervention program they overcame the fear of contracting the disease, myths were clarified, did not feel stigmatized and were willing to talk openly about the disease with others. They felt empowered, were able to understand that there was no specific cause for the disease. They were able to deal with the side effects of the treatment and did not panic especially when forced to face the side effects of chemotherapy. Their anxiety had decreased and they were able to take care of the patient well. They made up their minds to inculcate healthy life style habits and become change agents in their society. The study also depicted the following:

Acknowledging self worth: The care givers understood that they are an important person in the process of care giving and so they took care of themselves. They had their food in time and rested whenever it was possible which they were not doing prior to the intervention.

Acceptance of their limitations: They said that they were able to ask for help. Earlier they felt guilty to seek help and felt it was not right.

Seeking family support: The care givers realized that the other family members also need to take the responsibility of caring for the patient and so they took turns in caring for them.

De-stressing: The caregivers tried to bring out some humor in their situations. For example, a female patient was refusing to eat because her mouth was bitter after chemotherapy. During this period her spouse wasn't there. He had gone to the village to sell his crops. The other caregivers started to tease her by telling that she was fretting for her husband and only what he gives her will be sweet and not what they give her. This made the patient laugh and she ate to avoid being teased. Most of the caregivers said that they took a walk to the park in the hospital campus to de-stress themselves along with the patients and spent time talking with the others.

Social support: It was strengthened. For example one caregiver said that because of the social support, he was able to leave his patient (spouse) in the care of the other care givers in the ward and go to his village for three days. He was able to harvest the vegetables and sell it. Thus he made a profit. Another care giver, a student was able to leave her mother in the care of others and take up the examination. They helped her by taking her mother for radiation and meeting all her needs.

Interactions with the patient: The care givers shared the daily sessions with the patient. The interaction between them had improved drastically because earlier they were scared that it was a communicable disease. After the intervention program, there was enhancement in patient care, nutrition and hygiene of the patients. Patients did not panic when they had to face the side effects of the treatment as they and the care givers were aware and prepared for it. Patients said that the program was beneficial to them.

Street Play: All the caregivers said that the street play was useful for them and said that it would be more useful for the illiterate caregivers. It had prepared them to think and provoked them to ask more questions. They also gave their names and said that they wanted to be a part of the street play.

\section{Discussions}

It is obvious from the literature review and needs assessment that care givers had several needs and it must be addressed through interventions. This study supports this fact as all the caregivers said that the intervention program met their needs. However there was a need to further explore to what extent it was met. It also depicts that stigma, social isolation, stress, lack of support and personal limitations could be overcome through group activity as people with similar problems shared a common platform, ventilated, shared their experiences, helped each other and learned from each other. As a result the negative impact of care giving could be ameliorated. Literature has shown that decreased social activities would result in caregivers perceiving less support and becoming more involved in care giving disrupting their personal lives [26]. But, the present study showed strengthened social support and enhanced personal care after the intervention. They were also able to attend to their family needs by taking turns in care giving. The patient care was also enhanced as their fear of contracting the disease was overcome. They were able to make decisions as they had adequate knowledge about the disease.

\section{Conclusion}

Pyscho educational Intervention Program was effective in meeting the needs of the caregivers. The care givers were equipped to encounter the unforeseen problems, handle situations skillfully, make decisions, cope with the crisis, were able to seek family support and social support, maintained self care and imparted timely and proper care to the patient. Therefore intervention programs for caregivers of other types of cancer must be developed and implemented. There is a need for rigorous studies on the effectiveness of the program with a large population size. Further studies must be carried out to find out whether it ameliorates the negative impact of care giving.

Multi -component interventions could be used, for example psycho education along with counseling or cognitive behavioral therapy. Mixed interventions could also be incorporated in the intervention program i.e. 
combination of individual and group activities. There is also a need to see whether interventions delivered in the early and middle stages of the progressive disease are more effective than those delivered to caregivers in the later stage of the disease.

\subsection{Future Challenges}

In India, the health care professionals must recognize the needs of caregivers and understand the importance of developing such intervention programs, implementing and training others. The biggest challenge would be to motivate them to accept and include the care givers into the caring team. Another hurdle would be mobilizing resources for the program.

\section{References}

[1]. Doss, D. S. (2013). A pilot study to investigate concerns in patients undergoing neck dissection surgery.

[2]. Savant, D. (2011). Survival rate of head and neck cancer patients are decreasing due to late diagnosis. PRLog (Press Release).

[3]. Haman, K., L. (2008). Psychological Distress and Head and neck cancer: Part 1- Review of literature. Journal of Supportive Oncology, 6(4)

[4]. Watt-Watson J.\&Graydon J., (1995). Impact of surgery on head and neck cancer patients and their caregivers. Nursing Clin North America,30(4), 659-671. [PubMed: 7501534]

[5]. Esper, P. (2010). Symptoms cluster in individuals living with advanced cancer. Seminars in Oncology Nursing, 26, 168-164.

[6]. Marcusen, C. (2010). Information and communication needs of individuals living with advanced cancer.Seminars in Oncology Nursing, 26, 151-156.

[7]. Longacre, M. L., Ridge, J. A., Burtness, B.A., Galloway, T. J. \& Fang, C. Y. (2011). Psychological functioning of caregivers for head and neck cancer patients.Oral Oncol.48(1), 18-25.

[8]. Ronis, D. L., Duffy, S.A., Fowler, K.E., Khan, M. J. \& Terrell, J.E. (2008). Changes in quality of life over 1 year in patients with head and neck cancer.Arch Otalaryngol Head Neck Surgery, 134(3), 241-248.

[9]. Oates, J. E., Clark, J. R., Read, J. et al. (2007). Prospective evaluation of quality of life and nutrition before and after treatment for naso- pharyngeal carcinoma.Arch Otolaryndgol Head Neck Surgery, 133(6), 533-540.

[10]. Kagan, S. H., Clarke, S. P. \&Happ, M. B. (2005). Head and neck cancer patient and family member interest in use of E-mail to communicate with clinicians. Head Neck, 27(11), 976-81.

[11]. Giris, A. \& Lambert, S. (2009). Care givers of cancer survival: The state of the field. Cancer Forum, 33(3). Retrieved February 15, 2013 , from

/2009/November/Forum/Caregivers_of_cancer_survivors_the_state_of_the_field.htm.

[12]. Klem, P. \& Wheeler, E. (2005). Cancer caregivers online: hope, emotional roller coasterand physical/emotional/psychological responses. Computers.Informatics, Nursing, 23, 38-45.

[13]. Stenberg, U., Ruland, C. M. \&Miaskowski, C. (2010). Review of literature on the effects of caring for a patient with cancer Psycho-Oncology, 19(10): 1013-1025.[PubMed].

[14]. Wilkinson, A. M. (2010). The care experience in end-of life cancer caregiving: A discussion of the literature. Cancer Forum, 34.

[15]. Reinhard, S., C., Given, B., Petlick, N., H., \& Bemis, A. (2008). Supporting family caregivers in providing care. Patient safety and quality: an evidence based handbook for nurses. Rovkvillie(MD): Agency for healthcare Research and Quality (US).Retrieved from http://www.ncbi.nlm.nih.gov/books/NBK2665 on 1/23/2014.

[16]. Meecharoen, W., Northouse, L. L., Sirapo-ngam, Y. \&Monkong, S. (2013). Family caregivers for cancer patients in Thailand: an integrative review. Sage, p-1-10

[17]. Northouse, L. L. (2012). Helping patients and their family caregivers cope with cancer. OncolNurs Forum, 39(5), 500-506

[18]. Bultz, B. D., Speca, M., Brasher, P.M., Geggie, P. H. \& Page, S. A. (2000). A randomized controlled trial of a brief psychoeducational support group for partners of early stage breast cancer patients. Psych-Oncology, 9, 303-313.

[19]. Gibson, J. S., Horn, S.H., Powell, J.M. \&Gibbson, J. (1984). Schizopherenic patients and their families: a survey in psychiatric services based on a DGH unit. Br J Psychiatry, 144, 70-77.

[20]. Bulger, M. W., Wandersman, A. \& Goldman, C. R. (1993). Burdens and gratifications of caregiving: appraisal of parental care of adults with schizopherenia. Am J Orthopsychiatry, 63, 225-226.

[21]. Lehman, A., F. \&Steinwachs, D., M. (1998). Patterns of usual care for schizophrenia: initial results from the schizophrenia outcome research team treatment recommendations. Schizophernia Bull, 24, 11-20.

[22]. Dixon, L., Lucksted, A., Stewart, B., Burland, J., Brown, C. H., Postrado, L., McGuire, C. \& Hoffman, M. (2004). Outcomes of the peer-taught 12 week family to family education program for severe mental illness. ActaPsychiatrScand, 109, $207-215$.

[23]. Given, B., Sherwood, P., R. \& Given, C., W. (2008). What Knowledge and Skills Do Caregivers Need? American Journal of Nursing 108(94), 28-34.

[24]. Cochrane, B. \& Lewis, F.M. (2005). The parteners adjustment to breast cancer: a critical analysis of intervention studies. Health Psychology, 24, 327-332

[25]. Feinberg, L., L. (2008). Caregiver assessment.American Journal of Nursing. 108(9), 38-39.

[26]. Northouse, L. L., Katapodi, M.C., Song, L., Zhang,L.\& Mood, D. W. (2010). Interventions with family caregivers of cancer patients: meta-analysis of randomized trials. Cancer J Clin, 60(5), 317-339.

[27]. Schubart, J., R., Kinzie, M., B. \&Farace, E. (2008). Caring for the brain tumour patient: Family caregiver burden and unmet needs.Neuro-Oncology, 10, 61-72.

[28]. Baghi, M., Wagenblast, J., Hambek, M., Radeloff, A., Gstoettner, W., Scherzed, A., Spaenkuch, B., Yuan, J., Hornung, S., Strebhardt, K. \&Kenecht, R. (2007).Demands on caring relatives of head and neck cancer patients.The Laryngoscope, 117(4), 712716. [PubMed <http://www.ncbi.nlm.nih.gov/pubmed/15482862>-17415143].

[29]. Glajchen, M. (2004). The emerging role and needs of family care givers in cancer care. J Support Oncol.,4,145-155.

[30]. MacLennan, W. (1998). Caring for carers.Age and Ageing, 27,651-652.

[31]. Kulkurani, M. R. (2013). Head and neck cancer burden in India. International Journal of Head and Neck Dissection Surgery.4(1), 29-35.

[32] Argiris, A., Karamouzis, M., V., Raben, D. \& Ferris, R., L. (2008). Head and neck cancer, The Lancet, 391(9625), 1695-1709.

[33]. Ariyawardana, A. \& Johnson (2013). Trend of lip, oral cavity and oropharyngeal cancers in Australia 1982-2008: Overall good news but with rising rates in the oropharynx. BMC Cancer. 
[34]. Bhagyalaxmi, A. \&Raval, V.S. (2002). A study of the effects of illness experienced by families of oral and orapharyngeal cancer patients. Indian Journal of Community Medicine, 27(1), 30-34.

[35]. Teddilie, C. \&Tashakkori, A. (2003). Major issues and controversies in the use of mixed methods in the social and behavioral sciences. London: Sage Publications.

[36]. Lovibond, S., H. \&Lovibond, P., F. (1995). Manual for the depression, Anxiety, Stress Scales. $2^{\text {nd }}$ ed. Sydney: Psychological foundation

[37] Mehrotra, S. (2008). Psycho-Oncology research in India: current status and future directions. Journal of the Indian Academy of applied Psychology, 34(1), 7-18.

[38] Nijboer, C., Tempelaar, R., Sanderman, R., Triemstra, M., Spruijt, R. J. \& Van den Bos, G. A. (1998). Cancer and caregiving: the impact on the caregiver's health.Psychooncology, 7(1), 3-13. 